\title{
Correction to: Measuring Supply Chain Resilience
}

The updated version of this chapter can be found at $\mathbf{h t t p s}$ :// doi.org/10.1007/978-3-030-70490-2_4

(c) The Author(s), under exclusive license to Springer Nature Switzerland AG 2021

D. Ivanov, Introduction to Supply Chain Resilience,

Classroom Companion: Business,

https://doi.org/10.1007/978-3-030-70490-2_6 


\section{Correction to: Chapter 4 in: D. Ivanov, Introduction to Supply Chain Resilience, Classroom Companion: Business, - https://doi.org/10.1007/978-3-030-70490-2_4}

The original version of the chapter was inadvertently published with an error. The chapter has now been corrected.

On page 118, the lines 15,16 and 20 have been updated as follows:

$j$ is the product index, $j \in[1, \ldots, m]$.

$l_{j}$ is a part needed for product $j, l \in\left[1, \ldots, r_{j}\right]$.

$\mathrm{Q}_{l}$, is the total number of units of part $l$.

On page 119, the line 4 and equation 4.27 have been updated as follows:

$I_{k}$ is inventory (measured, e.g., as weeks of supply) held at the supply chain echelon $k$.

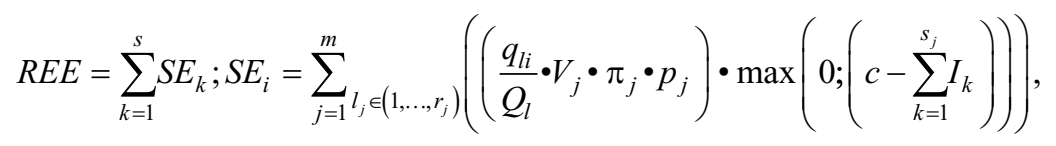

